\title{
A study on some basic features of inertial oscillations and near-inertial internal waves
}

\author{
Shengli Chen, Daoyi Chen, and Jiuxing Xing \\ Shenzhen Key Laboratory for Coastal Ocean Dynamic and Environment, Graduate School at Shenzhen, \\ Tsinghua University, Shenzhen 518055, China \\ Correspondence to: Jiuxing Xing (jxx2012@sz.tsinghua.edu.cn)
}

Received: 5 May 2017 - Discussion started: 31 May 2017

Revised: 8 September 2017 - Accepted: 12 September 2017 - Published: 17 October 2017

\begin{abstract}
Some basic features of inertial oscillations and near-inertial internal waves are investigated by simulating a two-dimensional $(x-z)$ rectangular basin $(300 \mathrm{~km} \times 60 \mathrm{~m})$ driven by a wind pulse. For the homogeneous case, nearinertial motions are pure inertial oscillations. The inertial oscillation shows typical opposite currents between the surface and lower layers, which is formed by the feedback between barotropic waves and inertial currents. For the stratified case, near-inertial internal waves are generated at land boundaries and propagate offshore with higher frequencies, which induce tilting of velocity contours in the thermocline. The inertial oscillation is uniform across the whole basin, except near the coastal boundaries $(\sim 20 \mathrm{~km})$, where it quickly declines to zero. This boundary effect is related to great enhancement of non-linear terms, especially the vertical non-linear term $(w \partial \boldsymbol{u} / \partial z)$. With the inclusion of near-inertial internal waves, the total near-inertial energy has a slight change, with the occurrence of a small peak at $\sim 50 \mathrm{~km}$, which is similar to previous research. We conclude that, for this distribution of near-inertial energy, the boundary effect for inertial oscillations is primary, and the near-inertial internal wave plays a secondary role. Homogeneous cases with various water depths $(50,40,30$, and $20 \mathrm{~m})$ are also simulated. It is found that near-inertial energy monotonously declines with decreasing water depth, because more energy of the initial wind-driven currents is transferred to seiches by barotropic waves. For the case of $20 \mathrm{~m}$, the seiche energy even slightly exceeds the near-inertial energy. We suppose this is an important reason why near-inertial motions are weak and hardly observed in coastal regions.
\end{abstract}

\section{Introduction}

Near-inertial motions have been observed and reported in many seas (e.g. Alford et al., 2016; Webster, 1968). They are mainly generated by changing winds at the sea surface (Pollard and Millard, 1970; Chen et al., 2015b). The passage of a cyclone or a front can induce strong near-inertial motions (D'Asaro, 1985), which can last for 1-2 weeks and reach a maximum velocity magnitude of $0.5-1.0 \mathrm{~m} \mathrm{~s}^{-1}$ (Chen et al., 2015a; Zheng et al., 2006; Sun et al., 2011). In deep seas, the near-inertial internal wave propagates downwards to transfer energy to depth (Leaman and Sanford, 1975; Fu, 1981; Gill, 1984; Alford et al., 2012). The strong vertical shear of near-inertial currents may play an important role in inducing mixing across the thermocline (Price, 1981; Burchard and Rippeth, 2009; Chen et al., 2016).

In shelf seas, near-inertial motions exhibit a two-layer structure, with an opposite phase between currents in the surface and lower layers (Malone, 1968; Millot and Crepon, 1981; MacKinnon and Gregg, 2005). By solving a two-layer analytic model using the Laplace transform, Pettigrew (1981) found this "baroclinic" structure can be formed by inertial oscillations without inclusion of near-inertial internal waves. Due to similar vertical structures and frequencies, inertial oscillations and near-inertial internal waves are hardly separable, and could easily be mistaken for each other.

In shelf seas, the near-inertial energy increases gradually offshore, and reaches a maximum near the shelf break, found in both observations (Chen et al., 1996) and model simulations (Xing et al., 2004; Nicholls et al., 2012). Chen and Xie (1997) reproduced this cross-shelf variation in both linear and non-linear simulations, and attribute it to large values of the cross-shelf gradient of surface elevation and the verti- 


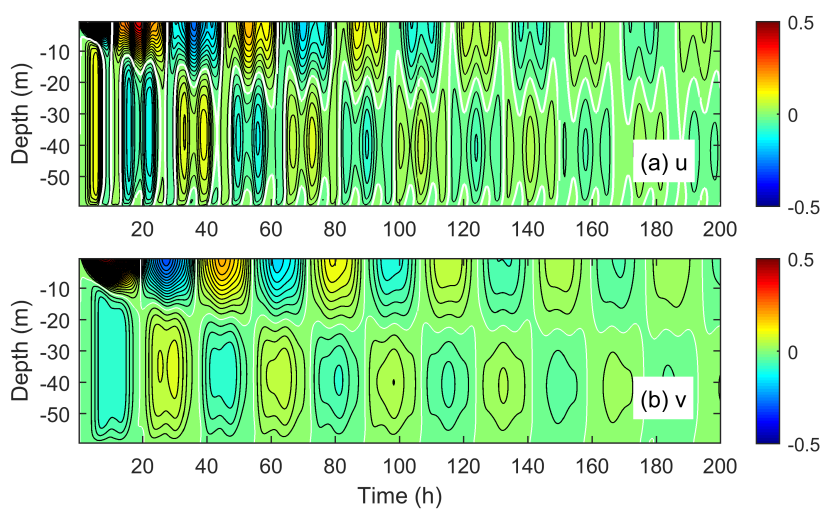

Figure 1. Velocities ( $u$ and $v, \mathrm{~m} \mathrm{~s}^{-1}$ ) at $x=70 \mathrm{~km}$. The white lines denote the value of zero. The contour interval is $0.02 \mathrm{~m} \mathrm{~s}^{-1}$ for both panels.
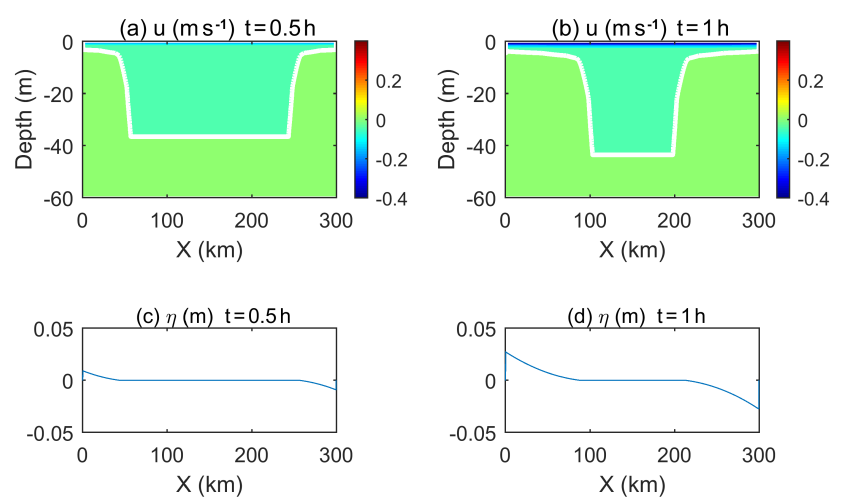

Figure 2. Snapshots of eastward velocity and elevation $(\eta)$ at $t=0.5$ and $1 \mathrm{~h}$. The white lines represent the value of zero.

cal gradient of Reynolds stress near the shelf break. By using the analytic model of Pettigrew (1981), Shearman (2005) argued that the cross-shelf variation is controlled by baroclinic waves which emanate from the coast to introduce nullifying effects on the near-inertial energy near the shore. Kundu et al. (1983) found a coastal inhibition of near-inertial energy within the Rossby radius from the coast, which is attributed to leaking of near-inertial energy downward and offshore. As many factors seem to work, the mechanism controlling the cross-shelf variation of near-inertial energy is not clear.

In this paper, simple two-dimensional simulations are used to investigate some basic features of near-inertial motions. Cases with and without vertical stratification are simulated to examine properties and differences between inertial oscillations and near-inertial internal waves. The horizontal distribution of near-inertial energy is discussed in detail. Also, cases with various water depths are simulated to investigate the dependence of near-inertial motions on the water depth.
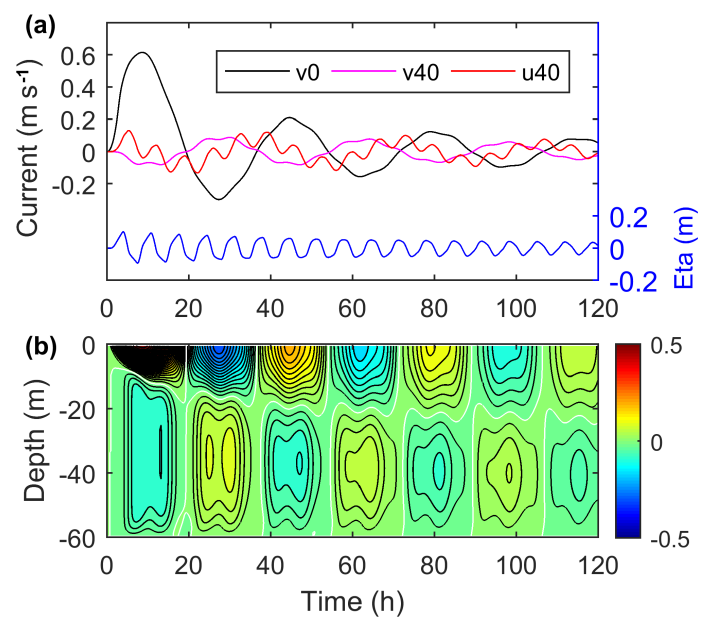

Figure 3. (a) Time series of velocities and elevation at $x=100 \mathrm{~km}$. "v0" and "v40" mean the northward velocity $(v)$ at depths of 0 and $40 \mathrm{~m}$, and " $\mathrm{u} 40$ " is the eastward velocity $(u)$ at $40 \mathrm{~m}$. (b) Contours of $v$ at $x=100 \mathrm{~km}$. The white lines denote the value of zero, and the contour interval is $0.02 \mathrm{~m} \mathrm{~s}^{-1}$.

\section{Model settings}

The simulated region is a two-dimensional shallow rectangular basin $(300 \mathrm{~km} \times 60 \mathrm{~m})$. Numerical simulations are done by the MIT general circulation model (MITgcm; Marshall et al., 1997), which discretizes the primitive equations and can be designed to model a wide range of phenomena. There are 1500 grid points in the horizontal $(\Delta x=200 \mathrm{~m})$ and 60 grid points in the vertical $(\Delta z=1 \mathrm{~m})$. The water depth is uniform, with the eastern and western sides being land boundaries. The vertical and horizontal eddy viscosities are assumed constant as $5 \times 10^{-4}$ and $10 \mathrm{~m}^{2} \mathrm{~s}^{-1}$, respectively. The Coriolis parameter is $5 \times 10^{-5} \mathrm{~s}^{-1}$ (at a latitude of $20.11^{\circ} \mathrm{N}$ ). The bottom boundary is non-slip. The model is forced by a spatially uniform wind which is kept westward and increases from 0 to $0.73 \mathrm{~N} \mathrm{~m}^{-2}$ (corresponding to a wind speed of $20 \mathrm{~m} \mathrm{~s}^{-1}$ ) for the first $3 \mathrm{~h}$ and then suddenly stops. The model runs for $200 \mathrm{~h}$ in total, with a time step of $4 \mathrm{~s}$. The first case is homogeneous, while the second one has a stratification of a two-layer structure initially. For the stratified case, the temperature is $20^{\circ} \mathrm{C}$ in the upper layer $(-30 \mathrm{~m}<\mathrm{z}<0)$ and $15^{\circ} \mathrm{C}$ in the lower layer $(-60 \mathrm{~m}<\mathrm{z}<-30 \mathrm{~m})$. The salinity is constant, and the density is linearly determined by the temperature, with an expansion coefficient of $2 \times 10^{-4}{ }^{\circ} \mathrm{C}^{-1}$. The barotropic and baroclinic Rossby radii are 485 and $8 \mathrm{~km}$, respectively.

\section{Inertial oscillations}

The first case is without the presence of vertical stratification. Thus the near-inertial internal wave is absent, and the nearinertial motion is a pure inertial oscillation. 


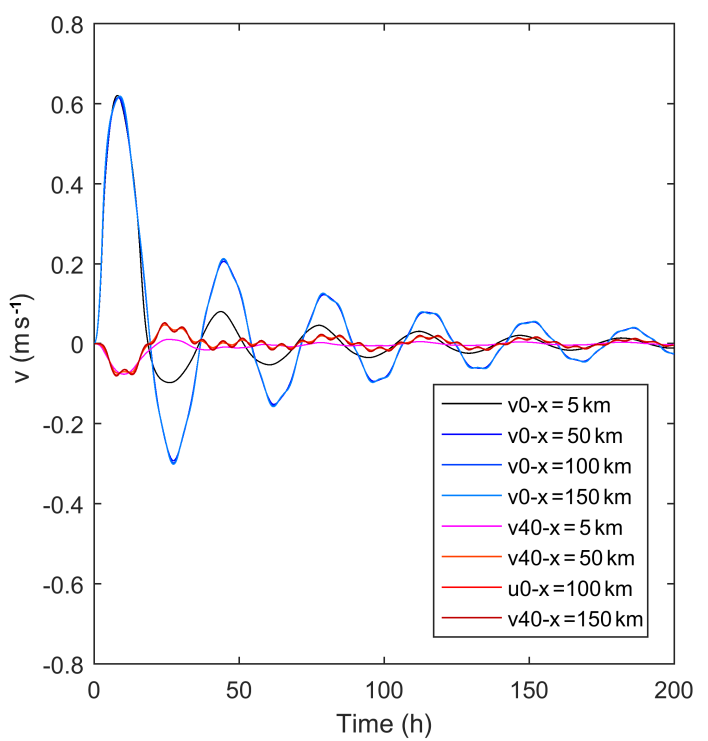

Figure 4. Time series of the northward velocity $(v)$ at different depths and positions. "v0" and "v40" mean $v$ at depths of 0 and $40 \mathrm{~m}$.

\subsection{Vertical structures}

The model simulated velocities (Fig. 1) vary near the inertial period ( $34.9 \mathrm{~h}$ ). Spectra of velocities (not shown) indicate maximum peaks located exactly at the inertial period. The spectra of $u$ also have a smaller peak at the period of the first mode seiche $(6.9 \mathrm{~h})$. As this simulation is two-dimensional, i.e. the gradient along the $y$-axis is zero, the $u / v$ of seiches have a value of $\omega_{n} / f$ (equals 5 for the first mode seiche). Thus there is little energy of seiches in $v$, which shows clearly regular variation at the inertial frequency.

In the vertical direction, currents display a two-layer structure, with their phase being opposite between the surface and lower layers. They are maximum at the surface, and have a weaker maximum in the lower layer $(\sim 40 \mathrm{~m})$, with a minimum at a depth of $\sim 20 \mathrm{~m}$. The velocity gradually diminishes to zero at the bottom due to the bottom friction. This is the typical vertical structure of shelf sea inertial oscillations, which have been frequently observed (Shearman, 2005; MacKinnon and Gregg, 2005). In practice, this vertical distribution can be modified due to the presence of other processes, such as the surface maximum being pushed down to the subsurface (e.g. Chen et al., 2015a). Note that without stratification in this simulation the near-inertial internal wave is absent. However, this two-layer structure of inertial oscillations looks 'baroclinic', which makes it easy to be mistakenly attributed to the near-inertial internal wave (Pettigrew, 1981).

It is interesting that currents of non-baroclinic inertial oscillations reverse between the surface and lower layers. This is usually due to the presence of the coast, which requires the normal-to-coast transport to be zero; thus, currents in the up-

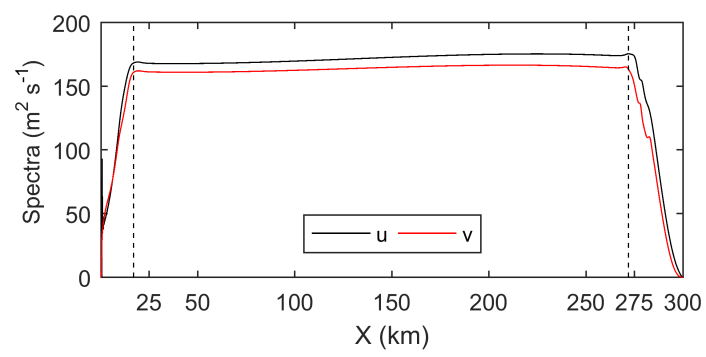

Figure 5. Spatial variation of depth-mean near-inertial spectra of velocities for the homogeneous case.
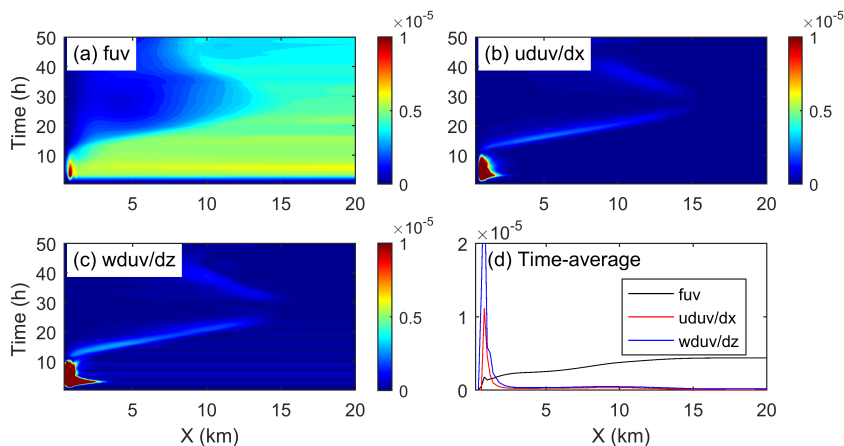

Figure 6. Variation of depth-mean inertial and non-linear terms $\left(\mathrm{m} \mathrm{s}^{-2}\right)$. The inertial term (a) is calculated as $|f(u+i v)|$, the horizontal non-linear term (b) is $|u(\partial u / \partial x+i \partial v / \partial x)|$, and the vertical non-linear term (c) is $|w(\partial u / \partial z+i \partial v / \partial z)|$. (d) Time-averaged value for the first $50 \mathrm{~h}$.

per and lower layers compensate each other (e.g. Millot and Crepon, 1981; Chen et al., 1996). However, it is interesting to see how this vertical structure is established step by step.

As the westward wind blows for the first $3 \mathrm{~h}$, the initial inertial current is also westward and only exists in the surface layer (Fig. 2). In the lower layer there is no movement initially. Thus a westward transport is produced, which generates a rise (in the west) and fall (in the east) in elevation near land boundaries. The elevation slope behaves in the form of a barotropic wave which propagates offshore at a large speed $\left(87 \mathrm{~km} \mathrm{~h}^{-1}\right)$. The current driven by the barotropic wave is eastward, and uniform vertically. Therefore, with the arrival of the barotropic wave the westward current in the surface is reduced, and the eastward movement in the lower layer commences (Fig. 2). After the passage of the first two barotropic waves (originating from both sides), currents in the lower layer have reached a relatively large value, while currents in the surface layer have largely decreased (Fig. 3a). Accordingly, the depth-integrated transport diminishes significantly. This is a feedback between inertial currents and barotropic waves. If only the depth-integrated transport of currents exists, barotropic waves will be generated, which reduce the surface currents but increase the lower layer currents and thus reduce the current transport. It will end up with iner- 

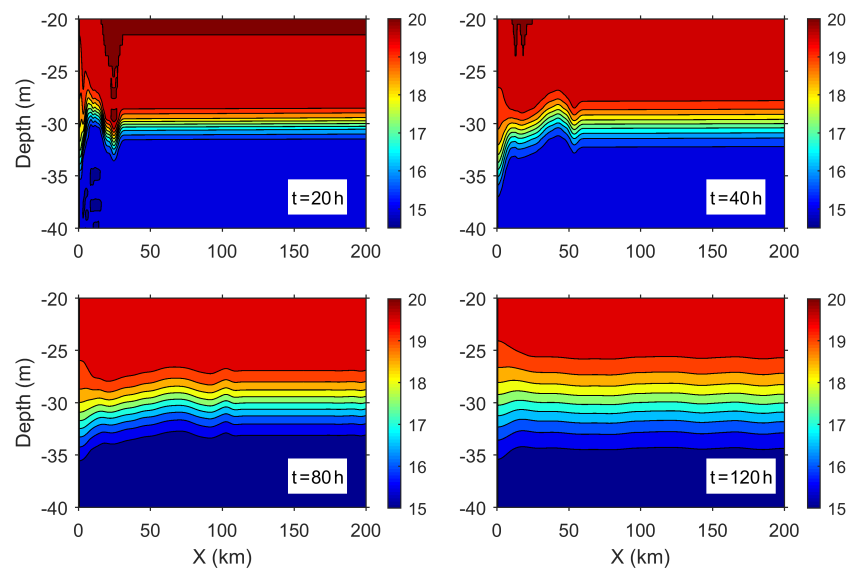

Figure 7. Snapshots of temperature profiles at $t=20,40,80$, and $120 \mathrm{~h}$. The contour interval is $0.5^{\circ} \mathrm{C}$.
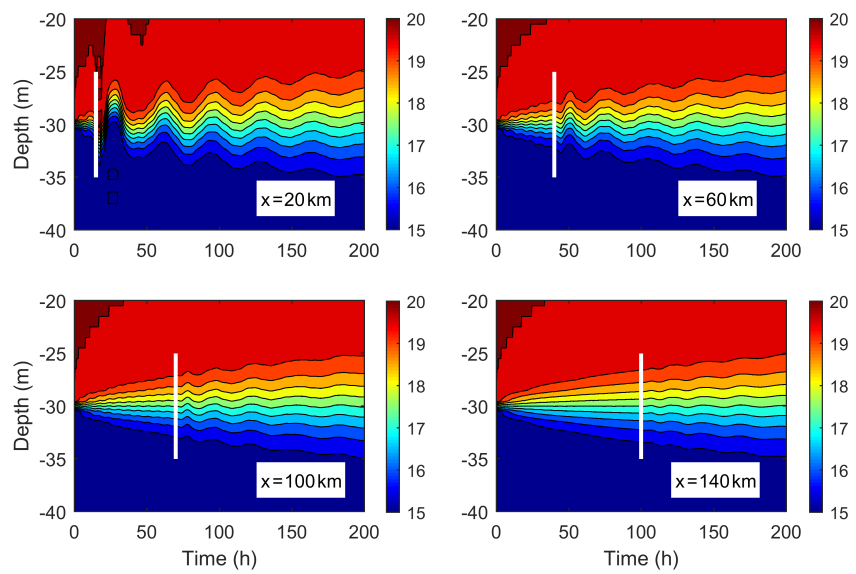

Figure 8. Time series of temperature at $x=20,60,100$, and $140 \mathrm{~km}$. White lines denote the arrival of internal waves. The contour interval is $0.5^{\circ} \mathrm{C}$.

tial currents in the surface and lower layers having opposite directions and comparable amplitudes. As seen from Fig. 1b, the typical vertical structure of inertial currents is established within the first inertial period.

\subsection{Horizontal distributions of inertial energy}

The inertial velocities are almost entirely the same across the basin (Fig. 4), except near the land boundaries. This indicates that inertial oscillations have a coherence scale of almost the basin width. This is because in our simulation the wind force is spatially uniform, and the bottom is flat. The inertial velocities in the lower layer have slightly more variation across the basin than those in the surface layer, because inertial velocities in the lower layer depend on the propagation of barotropic waves as discussed in Sect. 3.1, while the surface inertial currents are driven by spatially uniform wind. In shelf sea regions, the wind forcing is usually coherent as the synoptic scale is much larger; however, the topography
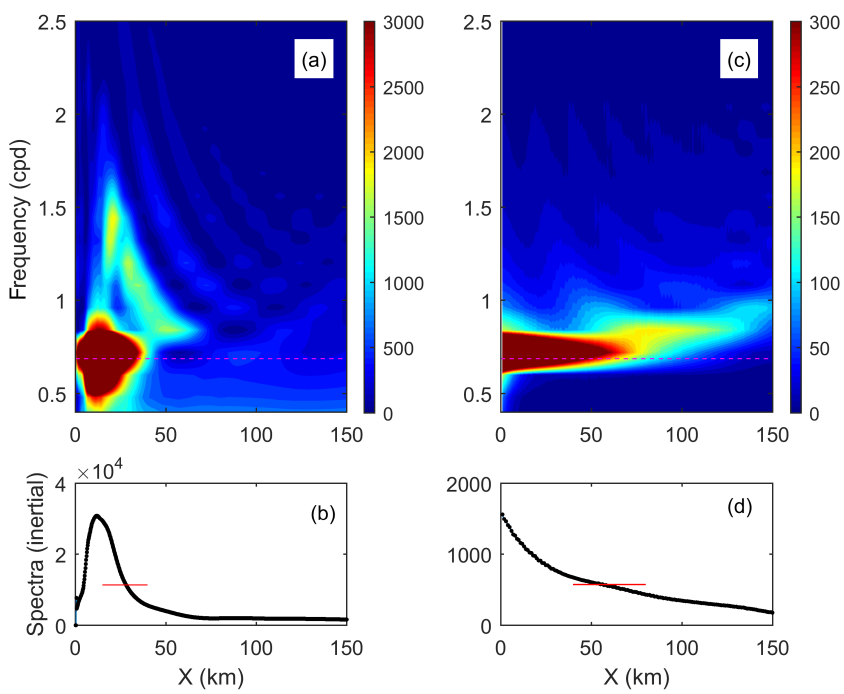

Figure 9. (a) Spectra of the temperature at the mid-depth $(z=$ $-30 \mathrm{~m})$. The pink dashed line represents the inertial frequency. (b) Sum of spectra in the inertial band with a red line denoting the e-folding value of the peak. (c) Theoretical spectra of mid-depth elevation calculated from the solution in the form of a Bessel function as in Eq. (3.16) of Pettigrew (1981). (d) Same as (b) but for theoretical spectra.
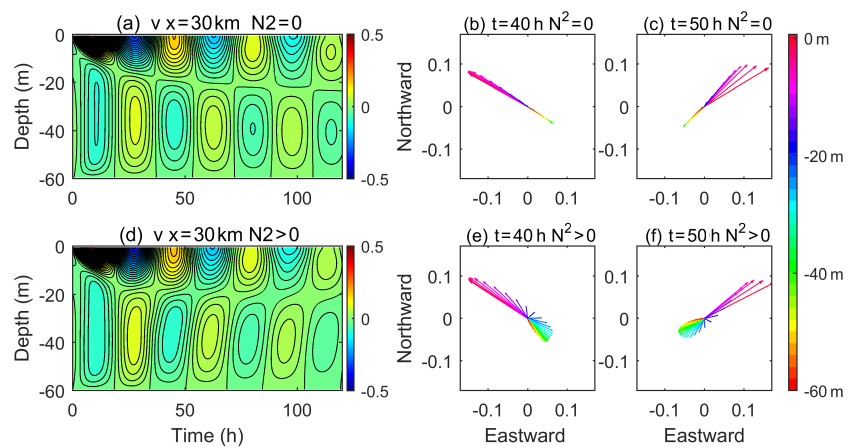

Figure 10. Distribution of near-inertial currents $\left(v, \mathrm{~m} \mathrm{~s}^{-1}\right)$ and current spirals for the cases without $(\mathbf{a}, \mathbf{b}, \mathbf{c})$ and with $(\mathbf{d}, \mathbf{e}, \mathbf{f})$ stratification at $x=30 \mathrm{~km}$. The near-inertial currents are obtained by applying a band-pass filter. The contour interval is $0.02 \mathrm{~m} \mathrm{~s}^{-1}$.

that is mostly not flat could generate barotropic waves at various places and thus significantly decrease coherence of inertial currents in the lower layer.

The spectra of velocities in the inertial band are almost uniform except near the land boundaries (Fig. 5), consistent with the velocities. Near the boundaries, the inertial energy declines gradually to zero from $x=\sim 20 \mathrm{~km}$ to the land. The eastern side has slightly greater inertial energy and a slightly wider boundary layer compared to the western side.

We calculate the non-linear and inertial terms in the momentum equation and find that non-linear terms are of significantly high value initially within $2 \mathrm{~km}$ away from the land 


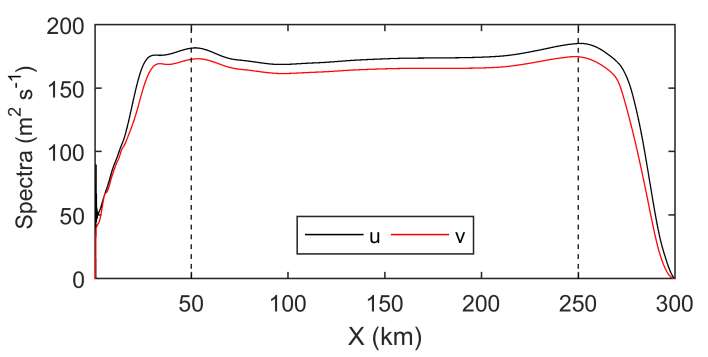

Figure 11. Spatial variation of depth-mean near-inertial spectra of velocities for the stratified case.

boundary (Fig. 6bc), where the inertial term is weak (Fig. 6a). For the time-averaged values (Fig. 6d), the vertical non-linear term is 2 times more than the horizontal non-linear term. The inertial term drops sharply near the boundary, and rises gradually with distance away from the boundary. At $x>15 \mathrm{~km}$, it keeps an almost constant value which is much greater than non-linear terms. Thus it is concluded that the significant decrease in inertial oscillations near the boundary is due to the influence of non-linear terms, especially the vertical nonlinear term.

\section{Near-inertial internal waves}

In addition to inertial oscillations, near-inertial internal waves are usually generated when the vertical stratification is present. However, due to their close frequencies, inertial oscillations and near-inertial internal waves are difficult to separate. Thus we run a second simulation with the presence of stratification to investigate the differences that near-inertial internal waves introduce.

\subsection{Temperature distributions}

Figure 7 shows the evolution of temperature profiles with time. One can see an internal wave packet is generated at the western coast and then propagates offshore. The wave phase speed is about $1 \mathrm{~km} \mathrm{~h}^{-1}$, close to the theoretical value $\left(1.4 \mathrm{~km} \mathrm{~h}^{-1}\right)$. Before the arrival of internal waves, the temperature at mid-depth diffuses gradually due to vertical diffusion in the model. For a fixed position at $x=20 \mathrm{~km}$ (Fig. 8), the temperature varies with the inertial period $(34.9 \mathrm{~h})$ and the amplitude of fluctuation declines gradually with time. At $x=60 \mathrm{~km}$ and $x=100 \mathrm{~km}$, the strength of internal waves is much reduced, and wave periods are shorter initially, followed by a gradual increase to the inertial period. At $x=140 \mathrm{~km}$, the internal wave becomes as weak as the background disturbance.

A spectral analysis of the temperature at mid-depth $(z=$ $-30 \mathrm{~m})$ is shown in Fig. 9a. The strongest peak is near the inertial frequency $(0.69 \mathrm{cpd})$, but is only confined to the region close to the boundary $(x<40 \mathrm{~km})$. In the region $20 \mathrm{~km}<x<70 \mathrm{~km}$, the energy is also large at higher fre-

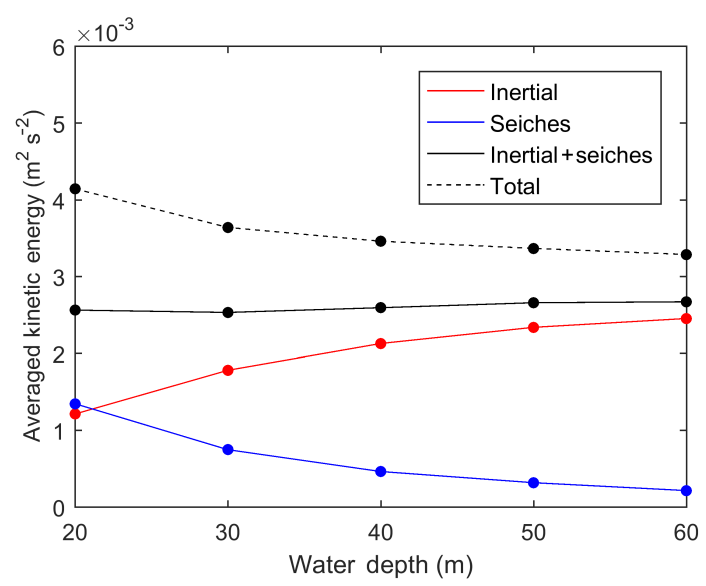

Figure 12. The kinetic energy of near-inertial motions and seiches for different water depths. For each case, the currents are band-pass filtered to get currents for each type of motion which are then averaged over time and integrated over space to obtain a final value.

quencies of $0.8-1.7 \mathrm{cpd}$. This generally agrees with properties of Poincaré waves. During Rossby adjustment, the waves with higher frequencies propagate offshore at greater group speeds; thus, for places further offshore, the waves have higher frequencies (Millot and Crepon, 1981), while the wave with a frequency closest to the inertial frequency moves at the slowest group velocity, and it takes a relatively long time to propagate far offshore; thus, it is mostly confined to near the boundary. By solving an idealized two-layer model equation, the response of Rossby adjustment can be expressed in the form of Bessel functions (Millot and Crepon, 1981; Gill, 1982; Pettigrew, 1981), as in Fig. 9cd showing the spectra of mid-depth elevation. The difference from our case is obvious. The frequency of theoretical near-inertial waves increases gradually with distance from the coast, while in our case this property is absent. And the theoretical inertial energy has an $e$-folding scale of $54 \mathrm{~km}$, while in our case the $e$-folding scale is much smaller $(\sim 15 \mathrm{~km})$.

\subsection{Velocity distributions}

With the presence of near-inertial internal waves, the contours of velocities near the thermocline tilt slightly (Fig. 10d), and indicate an upward propagation of phase and thus a downward energy flux. This can also be seen in vertical spirals of velocities (Fig. 10e and f). With only inertial oscillations, current vectors mostly point toward two opposite directions (Fig. 10b and c). Once the near-inertial wave is included, the current vectors gradually rotate clockwise with depth.

The spatial distribution of the near-inertial energy is also slightly changed compared to the case with only inertial oscillations (Figs. 11 and 5). It is also greatly reduced to zero in the boundary layer $(0-20 \mathrm{~km})$ like the case without stratification. But at $\sim 50 \mathrm{~km}$ away from the boundary the inertial 

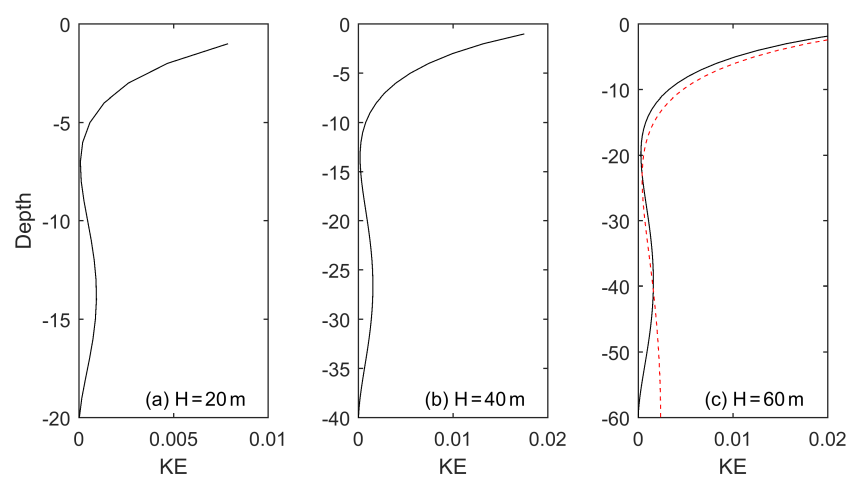

Figure 13. Vertical profile of averaged inertial kinetic energy for the homogeneous cases with water depths of 20,40 , and $60 \mathrm{~m}$. The red dashed line in (c) denotes the slip case.

energy reaches a peak. Further away $(>100 \mathrm{~km})$ it becomes a constant. This spatial distribution of inertial energy is similar to that observed in shelf seas, with a maximum near the shelf break (Chen et al., 1996; Shearman, 2005). In our case, the boundary layer effect which induces a sharp decrease to zero makes a major contribution, and near-inertial internal waves which bring a small peak further offshore have a secondary influence.

\section{Dependence on the water depth}

In coastal regions, near-inertial motions are rarely reported. It is speculated that the strong dissipation and bottom friction in coastal regions suppress the development of near-inertial motions. However, Chen (2014) found the water depth is also a sensitive factor, with significant reduction for the case with smaller water depth. Here we will run cases with different water depths and clarify why the near-inertial energy changes with water depth. Homogeneous cases with water depths of $50,40,30$, and $20 \mathrm{~m}$ are simulated. The vertical model resolution for all cases is $1 \mathrm{~m}$. All the other parameters including viscosities are the same as the homogeneous case of $60 \mathrm{~m}$.

For each case, the currents are band-pass filtered to obtain near-inertial currents. Then near-inertial kinetic energy can be calculated. As seen in Fig. 12, the near-inertial energy gradually declines with decreasing water depth. In this dynamical system, the other dominant process is the seiche induced by barotropic waves. As the elevation induced by seiches is anti-symmetric in such a basin, the potential energy is little. The kinetic energy of seiches can also be calculated by the band-pass filtered currents. We find the energy of seiches, by contrast, increases gradually with decreasing water depth. For the case of $60 \mathrm{~m}$, the near-inertial energy is much greater than the seiche energy. But for the case of $20 \mathrm{~m}$, the energy of seiches has exceeded the near-inertial energy slightly. The total energy of these two processes almost stays constant for all cases. For a shallower water depth, the re- duction of near-inertial energy equals the increase in seiche energy. The initial current is wind-driven and only distributes in the surface layer. The unbalanced across-shelf flow generates elevation near the land boundary which propagates offshore as barotropic waves and forms seiches. Part of the energy goes to form inertial oscillations. For a shallower water depth, the elevation is enlarged, and more energy is transferred to form seiches and thus with weakened near-inertial motions. Therefore, in coastal regions with water depths less than $30 \mathrm{~m}$, the near-inertial motion is weak, due to the suppression of barotropic waves.

As seen in Sect. 3.1, inertial oscillations behave in a twolayer structure, with currents in the upper layer in opposite phase with those of the lower layer. In terms of kinetic energy, for the case of $60 \mathrm{~m}$ (Fig. 13), the near-inertial motion is maximized in the surface, minimized near the depth of $20 \mathrm{~m}$, and then gradually increases with depth to form a much smaller peak at $40 \mathrm{~m}$. Near the bottom, the near-inertial energy gradually reduces to zero due to bottom friction. When we set the bottom boundary condition from non-slip to slip, such a boundary structure vanishes, and near-inertial energy becomes constant in the lower layer. For the other cases of 20 and $40 \mathrm{~m}$, their vertical profiles are almost the same as the $60 \mathrm{~m}$ case. The minimum positions are all located at $1 / 3$ of the water depth. This implies the vertical distribution of near-inertial energy is independent of water depth. Note that in our cases the vertical viscosity is set as a constant value. In practice, the viscosity in the thermocline is usually significantly reduced; thus, the minimum position of near-inertial energy is located just below the mixed layer.

\section{Summary and discussion}

Idealized simple two-dimensional $(x-z)$ simulations are conducted to examine the response of a shallow closed basin to a wind pulse. The first case is homogeneous, in which the near-inertial motion is a pure inertial oscillation. It has a twolayer structure, with currents in the surface and lower layers being opposite in phase, which has been reported frequently in shelf seas. We find that the inertial current is confined in the surface layer initially. The induced depth-integrated transport generates barotropic waves near the boundaries which propagate quickly offshore. The flow driven by the barotropic wave is independent of depth and opposite to the surface flow. Thus the surface flow is reduced but the flow in the lower layer is increased; as a result, the transport diminishes. This feedback between barotropic waves and currents continues and ends up with the depth-integrated transport vanishing, i.e. inertial currents in the upper and lower layers having opposite phases and comparable amplitudes. In our simulation, within just one inertial period the typical structure of inertial currents has been established. By solving a two-layer analytic model using the Laplace transform, Pettigrew (1981) also found the vertical structure of opposite 
currents to be associated with inertial oscillations. He argued that the arrival of a barotropic wave for a fixed location cancels half of the inertial oscillation in the surface layer, and initiates an equal and opposite oscillation in the lower layer. However, in our simulation the arrival of the first barotropic wave cannot cancel half of the surface flow. The balanced state of upper and lower flows takes more time to reach.

The second case is a set-up with idealized two-layer stratification; thus, near-inertial internal waves are generated. For a fixed position, velocity contours show obvious tilting near the thermocline, and velocity vectors display clearly anticyclonic spirals with depth. These could be useful clues to examine the occurrence of near-inertial internal waves. Near the land boundary the vertical elevation generates fluctuations of the thermocline that propagate offshore. The energy of near-inertial internal waves is confined to near the land boundary $(x<40 \mathrm{~km})$. At positions further offshore, the waves have higher frequencies. This is generally consistent with properties of a Rossby adjustment process. However, our simulated results also show evident discrepancies with theoretical values obtained in the classic solutions of the Rossby adjustment problem. These discrepancies are probably due to non-linearity of the model and the changing stratification in the model due to diffusion and mixing, compared to constant density differences between the two layers in theoretical cases.

The inertial oscillation has a very large coherent scale of almost the whole basin scale. It is uniform in both amplitude and phase across the basin, except near the boundary ( $\sim 20 \mathrm{~km}$ offshore). The energy of inertial oscillations declines gradually to zero from $x=20 \mathrm{~km}$ to the coast. This boundary effect is attributed to the influence of nonlinear terms, especially the vertical term $(w \partial \boldsymbol{u} / \partial z)$, which is greatly enhanced near the boundary and overweighs the inertial term $(f \boldsymbol{u})$. When near-inertial internal waves are produced in the stratified case, the distribution of total nearinertial energy is modified slightly near the boundary. A small peak appears at $\sim 50 \mathrm{~km}$ offshore. This is similar to the cross-shelf distribution of near-inertial energy observed in shelf seas (Chen et al., 1996; Shearman, 2005). This energy distribution has been attributed to downward and offshore leakage of near-inertial energy near the coast (Kundu et al., 1983), the variation of elevation and Reynolds stress terms associated with the topography (Chen and Xie, 1997), and the influence of the baroclinic wave (Shearman, 2005; Nicholls et al., 2012). In our simulations, this horizontal distribution of near-inertial energy is primarily controlled by the boundary effect on inertial oscillations, and the near-inertial internal wave has a secondary effect.

Homogeneous cases with various water depths (50, 40, 30, and $20 \mathrm{~m}$ ) are also simulated. The inertial energy is reduced with decreasing water depth, while the energy of seiches, by contrast, is increased. For the case of $20 \mathrm{~m}$, the seiche energy slightly exceeds the inertial energy. It is interesting that the reduction of inertial energy just equals the increase in the seiche energy, which implies more energy of initial winddriven currents is transferred to the seiches for the shallower cases, and thus less energy goes to the inertial process. This is probably an important reason why near-inertial motions are weak and rarely reported in shallow coastal regions.

Data availability. All the data can be obtained by contacting the authors.

Competing interests. The authors declare that they have no conflict of interest.

Acknowledgements. We are grateful for discussions with John Huthnance and comments from the editor and reviewers. This study is supported by the National Basic Research Program of China (2014CB745002, 2015CB954004), the Shenzhen government (201510150880, SZHY2014-B01-001), and the Natural Science Foundation of China (U1405233). Shengli Chen is sponsored by the China Postdoctoral Science Foundation (2016M591159).

Edited by: Neil Wells

Reviewed by: two anonymous referees

\section{References}

Alford, M. H., Cronin, M. F., and Klymak, J. M.: Annual Cycle and Depth Penetration of Wind-Generated Near-Inertial Internal Waves at Ocean Station Papa in the Northeast Pacific, J. Phys. Oceanogr., 42, 889-909, https://doi.org/10.1175/jpo-d-11-092.1, 2012.

Alford, M. H., MacKinnon, J. A., Simmons, H. L., and Nash, J. D.: Near-Inertial Internal Gravity Waves in the Ocean, Ann. Rev. Mar. Sci., 8, 95-123, https://doi.org/10.1146/annurev-marine010814-015746, 2016.

Burchard, H. and Rippeth, T. P.: Generation of Bulk Shear Spikes in Shallow Stratified Tidal Seas, J. Phys. Oceanogr., 39, 969-985, 10.1175/2008jpo4074.1, 2009.

Chen, C. and Xie, L.: A numerical study of wind-induced, near-inertial oscillations over the Texas-Louisiana shelf, J. Geophys. Res.-Oceans, 102, 15583-15593, https://doi.org/10.1029/97jc00228, 1997.

Chen, C. S., Reid, R. O., and Nowlin, W. D.: Near-inertial oscillations over the Texas Louisiana shelf, J. Geophys. Res.-Oceans, 101, 3509-3524, https://doi.org/10.1029/95jc03395, 1996.

Chen, S.: Study on Several Features of the Near-inertial Motion, PhD, Xiamen University, 107 pp., 2014.

Chen, S., Hu, J., and Polton, J. A.: Features of near-inertial motions observed on the northern South China Sea shelf during the passage of two typhoons, Acta Oceanol. Sin., 34, 38-43, https://doi.org/10.1007/s13131-015-0594-y, 2015a.

Chen, S., Polton, J. A., Hu, J., and Xing, J.: Local inertial oscillations in the surface ocean generated by time-varying winds, 
Ocean Dynam., 65, 1633-1641, https://doi.org/10.1007/s10236015-0899-6, 2015b.

Chen, S., Polton, J. A., Hu, J., and Xing, J.: Thermocline bulk shear analysis in the northern North Sea, Ocean Dynam., 66, 499-508, https://doi.org/10.1007/s10236-016-0933-3, 2016.

D'Asaro, E. A.: The energy flux from the wind to near-inertial motions in the surface mixed layer, J. Phys. Oceanogr., 15, 10431059, 1985.

Fu, L. L.: Observations and models of inertial waves in the deep ocean, Rev. Geophys., 19, 141-170, https://doi.org/10.1029/RG019i001p00141, 1981.

Gill, A. E.: Atmosphere-ocean dynamics, Academic Press, 662 pp., 1982.

Gill, A. E.: On the behavior of internal waves in the wakes of storms, J. Phys. Oceanogr., 14, 1129-1151, https://doi.org/10.1175/15200485(1984)014<1129:otboiw>2.0.co;2, 1984.

Kundu, P. K., Chao, S. Y., and McCreary, J. P.: Transient coastal currents and inertio-gravity waves, Deep-Sea Res. Pt. I, 30, 1059 1082, https://doi.org/10.1016/0198-0149(83)90061-4, 1983.

Leaman, K. D. and Sanford, T. B.: Vertical energy propagation of inertial waves: a vector spectral analysis of velocity profiles, J. Geophys. Res., 80, 1975-1978, 1975.

MacKinnon, J. A. and Gregg, M. C.: Near-inertial waves on the New England shelf: The role of evolving stratification, turbulent dissipation, and bottom drag, J. Phys. Oceanogr., 35, 2408-2424, https://doi.org/10.1175/jpo2822.1, 2005.

Malone, F. D.: An analysis of current measurements in Lake Michigan, J. Geophys. Res., 73, 7065-7081, https://doi.org/10.1029/JB073i022p07065, 1968.

Marshall, J., Adcroft, A., Hill, C., Perelman, L., and Heisey, C.: A finite-volume, incompressible Navier Stokes model for studies of the ocean on parallel computers, J. Geophys. Res.-Oceans, 102, 5753-5766, https://doi.org/10.1029/96jc02775, 1997.
Millot, C. and Crepon, M.: Inertial oscillations on the continentalshelf of the Gulf of Lions - observations and theory, J. Phys. Oceanogr., 11, 639-657, https://doi.org/10.1175/15200485(1981)011<0639:iootcs>2.0.co;2, 1981.

Nicholls, J. F., Toumi, R., and Budgell, W. P.: Inertial currents in the Caspian Sea, Geophys. Res. Lett., 39, L18603, https://doi.org/10.1029/2012gl052989, 2012.

Pettigrew, N. R.: The dynamics and kinematics of the coastal boundary layer off Long Island, 1981.

Pollard, R. T. and Millard, R. C.: Comparison between ovserved and simulated wind-generated inertial oscillations, Deep-Sea Res., 17, 813-821, 1970.

Price, J. F.: Upper ocean response to a hurricane, J. Phys. Oceanogr., 11, 153-175, https://doi.org/10.1175/15200485(1981)011<0153:uortah>2.0.co;2, 1981.

Shearman, R. K.: Observations of near-inertial current variability on the New England shelf, J. Geophys. Res., 110, C02012, https://doi.org/10.1029/2004jc002341, 2005.

Sun, Z., Hu, J., Zheng, Q., and Li, C.: Strong near-inertial oscillations in geostrophic shear in the northern South China Sea, J. Oceanogr., 67, 377-384, https://doi.org/10.1007/s10872-0110038-z, 2011.

Webster, F.: Observation of inertial period motions in the deep sea, Rev. Geophys., 6, 473-490, 1968.

Xing, J. X., Davies, A. M., and Fraunie, P.: Model studies of near-inertial motion on the continental shelf off northeast Spain: A three-dimensional two-dimensional one-dimensional model comparison study, J. Geophys. Res.-Oceans, 109, C01017, https://doi.org/10.1029/2003jc001822, 2004.

Zheng, Q., Lai, R. J., and Huang, N. E.: Observation of ocean current response to 1998 Hurricane Georges in the Gulf of Mexico, Acta Oceanol. Sin., 25, 1-14, 2006. 